\title{
A DEMOCRACIA, A SOCIEDADE E OS PARTIDOS POLÍTICOS: UMA ANÁLISE DA EVENTUAL EXISTÊNCIA DE UMA CRISE DAS ORGANIZAÇÕES PARTIDÁRIAS
}

\author{
Ana Claudia Santano ${ }^{1}$ \\ Katya Kozicki ${ }^{2}$
}

\begin{abstract}
Resumo
A atuação dos partidos junto à sociedade, no exercício de sua representação junto ao Estado desperta o questionamento sobre a necessidade (ou não) de sua existência e coloca o debate no centro da discussão acadêmica e também da agenda política em diferentes partes do mundo. Este trabalho busca questionar se há, de fato, uma crise, investigando a sua eventual extensão e consequências para a democracia. Para tanto, faz-se inicialmente uma revisão da literatura sobre o assunto, trabalhando os principais argumentos a favor e contra a existência dos partidos, para logo analisar conjuntamente as funções que tradicionalmente lhes foram atribuídas. Ao final, conclui-se que a crise não está nos partidos enquanto organizações, mas sim nos problemas de execução de suas funções.
\end{abstract}

Palavras-chave: Democracia; partidos políticos; representação política; crise; instituições públicas.

\section{INTRODUÇÃO}

É fato que os partidos políticos não são uma unanimidade na sociedade e que geram sentimentos e percepções antagônicas. Se há política, há partidos, uma vez que a sua existência é necessária para qualquer regime democrático. No entanto, eles também estão diretamente vinculados ao lado mais "nebuloso" das instituições públicas, ostentando talvez a posição mais "incômoda” dentro desta arena. A trajetória histórica dos partidos tem acompanhado o próprio desenvolvimento das sociedades democráticas ocidentais, já que, desde o século XIX, os partidos políticos foram se incorporando paulatinamente à cena pública, servindo como suportes de demandas sociais específicas dos grupos que representam, ou de igual maneira reivindicando direitos dos cidadãos frente ao

\footnotetext{
${ }^{1}$ Período de pesquisa pós-doutoral em Direito Público Econômico pela Pontifícia Universidade Católica do Paraná. Professora do programa de mestrado em Direitos Fundamentais e Democracia, do Centro Universitário Autônomo do Brasil - Unibrasil. E-mail: anaclaudiasantano@yahoo.com.br

${ }^{2}$ Doutora em Direito, Política e Sociedade pela Universidade Federal de Santa Catarina (2000). Professora dos programas de graduação e pós-graduação em Direito da Pontíficia Universidade Católica do Paraná e da Universidade Federal do Paraná. Visiting researcher associate, Centre for the Study of Democracy, University of Westminster, Londres (1998-1999). Visiting research scholar, Benjamin N. Cardozo School of Law, Nova York (2012-2013). Bolsista de produtividade em pesquisa do CNPq. E-mail:kkozicki@uol.com.br
} 
Estado.

A história também trouxe à tona as diversas dificuldades que os partidos enfrentam, não somente frente a uma democracia também mutável e que se desenvolve a sua maneira, mas também diante de uma sociedade denominada como pós-moderna, como é a atual, que sofreu transformações profundas em suas necessidades, demandas e modo de mobilização (Lipovetsky, 1986, p.79 e ss.). Por outro lado, a existência e a continuidade, dos partidos sempre estiveram longe de formar um consenso e, ao que parece, o momento de uma total aceitação destas organizações ainda está distante. As políticas e os governos podem ser coordenados por tais organizações, porém podem não mais permitir que eles conquistem o apoio social que gozavam até algumas décadas atrás e que, pouco a pouco, foram perdendo, como um reflexo do próprio distanciamento das esferas de poder da população em geral. Isto está claro em muitos países, não sendo o Brasil uma exceção. Um sinal disto foram os inúmeros protestos realizados pelos cidadãos brasileiros que mostraram à nação o atual rechaço dos partidos e uma desconfiança em niveis preocupantes sobre a própria legitimidade das instituições públicas onde eles atuam. Os movimentos de junho de 2013, também conhecidos como jornadas de junho, representam bem o grau de distanciamento da população em geral dos partidos políticos, que deixaram de ser o canal de reivindicações na esfera pública.

A doutrina tampouco integrou positivamente os partidos de maneira imediata. A sua aceitação foi resultado de um lento processo, e apesar de não estar totalmente convencida da idoneidade de tais organizações na direção dos assuntos públicos, a doutrina não dificultou a sua posterior adoção como instrumentos vitais à democracia moderna. Se as primeiras análises realizadas sobre os partidos não foram muito favoráveis - como o caso de OSTROGORSKI e MICHELS (Ostrogorski, 2008; Michels, 1996) - com o passar do tempo, tais organizações foram sendo inseridas na sociedade. Contudo, há quem ainda não os considere uma instituição em seu sentido mais genuíno (Colomer, 2001, p. 16), o que novamente os põe em uma posição um tanto dúbia na dinâmica sociedade-Estado.

A partir da análise crítica dos argumentos a favor e contra os partidos, pretende-se reacender o debate sobre a aceitação ou não destas organizações nas democracias contemporâneas, ou mesmo avaliar se é possível a sua substituição por outro tipo de ente sócio-político. O que se propõe aqui é um exame da importância destas formações políticas, do seu papel frente à sociedade, das conseqüências das mudanças havidas nos últimos anos tanto nas suas estruturas, quanto em seu entorno e, principalmente, da sua sobrevivência no futuro. Afinal, existe realmente uma crise de partidos?

Para tanto, utilizou-se como marco teórico alguns autores que se entende como "chaves" na Filosofia Política e Jurídica, na Ciência Política e na Sociologia, sempre dialogando com o Direito. Tratou-se de aglutinar em dois grupos as mais diversas opiniões sobre os partidos, para logo expor o que parece ser o verdadeiro cerne do 
problema: o cumprimento das funções dos partidos na sociedade moderna.

Contudo, o argumento a ser explorado na busca de respostas a esta questão orienta-se não no sentido de ser contra ou a favor dos partidos, de se posicionar em um ou outro lado, mas sim no de acrescentar no debate outros elementos que ultrapassam esta dicotomia. Verificar-se-á se os partidos não foram vítimas de si mesmos, em uma clara alusão a algum eventual abuso de poder que terminou conduzindo-os à rejeição popular, ou se simplesmente eles já não conseguem mais atingir seus objetivos dentro da democracia, tornando-se incapazes de lidar com a complexidade da sociedade moderna atual.

\section{ESCLARECIMENTOS PRELIMINARES}

Primeiramente, cabe uma ressalva antes do início da análise: não será possível trazer uma comprovação empírica dos argumentos aqui expostos. Isto porque, embora existam algumas pesquisas sobre os partidos políticos de muitos países democráticos do Ocidente, estas não raras vezes refletem e tomam como base uma crise que parece ser dos elementos da própria democracia, e não dos partidos propriamente ditos. A crise de representatividade, que freqüentemente resulta em uma crise de participação política, logicamente alcança os partidos, porém não se refere exatamente a uma crise destas organizações, por mais que eles sejam os principais atores da democracia e que muito provavelmente tenham colaborado para o recrudescimento deste descontentamento. Além disto, não é exagerado dizer que tais pesquisas acabam refletindo opiniões condicionadas pelo entorno que os cidadãos entrevistados vivem. Portanto, os dados ajudam a captar certas mensagens de insatisfação ou inclusive de desafetação política, mas quiçá não sejam os mais adequados para medir uma real crise de partidos em seu aspecto científico. ${ }^{3}$

Entretanto, parece oportuno ao menos trabalhar ao menos uma destas pesquisas, de modo a delinear a dimensão do problema posto. Nesse viés, expõe-se a estatística realizada pela Transparência Internacional e divulgada por meio do estudo anual do Global Corruption Barometer, no qual há dados sobre quais instituições públicas são valoradas como as mais corruptas, por país. No caso do Brasil, no último estudo realizado em 2013, $81 \%$ dos entrevistados indicaram os partidos políticos como a instituição mais corrupta no território brasileiro (Transparency International, 2013). Embora a metodologia empregada pela Transparência Internacional possa distorcer a opinião manifestada e possa não ser representativa (já que são entrevistados menos de 1000 pessoas de cada país estudado e, no caso brasileiro, tal amostra pode ser considerada como não expressiva), o resultado não pode ser ignorado. Ainda que o tema da corrupção seja bastante delicado no contexto brasileiro, estas informações demonstram que os partidos estão conectados a esta imagem de corrupção para os cidadãos brasileiros e não mais

\footnotetext{
${ }^{3}$ Como exemplo, cf. <<http://ec.europa.eu/public_opinion/archives/eb/eb74/eb74_publ_en.pdf〉> (especialmente p. 29). Acesso em 24 abr. 2014.
} 
a uma imagem que os identifica como um ator democrático, importantes na condução de assuntos públicos.

Obviamente que os próprios partidos contribuem para este mau julgamento, uma vez que, nas últimas décadas, eles protagonizaram grandes escândalos de corrupção trazidos a público, sem reagir contra os seus efeitos negativos ou mesmo esboçar alguma providência neste sentido. Pelo contrário: os partidos se envolveram ainda mais em novos casos de corrupção, sem uma devida punição interna e externa que eventualmente poderiam ser devidas (Villoria Mendieta, 2006, p. 205). Ressalte-se que o problema envolvendo corrupção e os partidos políticos não se limita ao Brasil, sendo este um fenômeno mundial.

Por outro lado, é necessário explicitar a própria noção de partido político com a qual se está trabalhando. Mesmo que não exista um consenso sobre o conceito de partidos políticos, há algumas características que usualmente se apresentam e que podem ser utilizadas em sua definição (Sartori, 1976, p. 64; Cotarelo, 1985, p. 11 15; Ware, 1996, p. 2-6; Carbone, 2003, p. 486). Assim, adotar-se-á neste trabalho um conceito mais amplo elaborado por Scott MAINWARING y Timothy R. SCULLY, que engloba não somente os partidos mas também os grupos políticos. Os autores entendem que um grupo político também pode ser um partido se ele puder apresentar candidatos para cargos públicos, mas que não o faz ou porque estão vedados de fazê-lo, ou porque não se celebram eleições (Mainwaring e Scully, 1995, p. 2). Trata-se de um conceito amplo que permite incluir um maior número de países, já que a ora debatida crise dos partidos não afeta somente o Brasil - como já dito - mas envolve a maioria dos países que se organizam dentro dos princípios da democracia liberal e representativa. Portanto, excluir estes grupos políticos poderia comprometer a análise proposta, uma vez que cada país possui normas distintas para regular a criação e formação dos partidos políticos, bem como a apresentação de candidaturas sem a outorga do monopólio desta função a estas agremiações.

Como base para este debate, o estudo dos partidos políticos e do desenvolvimento da política realizado há quarenta anos por LA PALOMBARA y WEINER dizia que a institucionalização e expansão dos partidos eram elementos essenciais para as políticas democráticas, e que era correto afirmar naquele período que o desenvolvimento de tais organizações era um fundamento para a evolução da política. Entretanto, com o passar dos anos, e principalmente na América Latina, este progresso não se concretizou da forma prevista (La Palombara, 2007, p. 141-154). Na Europa ocidental, iniciou-se um processo de erosão da mobilização dos partidos políticos, antes composta pela identificação partidária e pela confiança nestas organizações (Dalton e McAllister, 2007, p. 139), fenômeno que terminou se expandindo a muitos outros países não pertencentes aquele continente. É neste contexto que os partidos, já bastante modificados na sua essência desde a sua origem, são frequentemente questionados em seu papel frente ao Estado, principalmente quando esta separação entre os partidos e o Estado parece ser tão pouco visível e tão pouco percebida aos olhos dos cidadãos.

\section{OS ARGUMENTOS A FAVOR DOS PARTIDOS POLITICOS}


Por mais polêmicas que possam ser, as organizações partidárias seguem tendo a opinião pública majoritariamente a seu favor, ainda que com ressalvas. Se for considerar o estudo anteriormente citado de LA PALOMBARA e aplicá-lo aos dias de hoje, não apenas será possível confirmar suas hipóteses, como também negar esta suposta crise dos partidos. Segundo o próprio autor, os partidos são onipresentes, seja qual for a forma de Estado e nos mais variados sistemas políticos e de governo. Inclusive as ditaduras e os sistemas totalitários não seriam possíveis se não houvesse, pelo menos, um partido na sua estrutura (La Palombara, 2007, p. 143). Como ilustração disto, tem-se que, mesmo em lugares onde se buscou um outro modelo democrático, o fenômeno partidário terminou intetegrando-o, como é o caso das ilhas do Pacífico, ainda que em algumas a democracia sem partidos resista, como no caso da Micronésia (Rich, Hambly e Morgan, 2008). No entanto, podem existir exceções, modelos que conseguem se apartar dos partidos, como é o caso de eleições municipais em diversas cidades dos Estados Unidos - como Nova Yorque - em que se realizam processos eleitorais com muitos candidatos que não são indicados por partidos. É o que se denomina de nonpartisan elections, realizadas não só para cargos políticos, mas também para o preenchimento de outros cargos, como o de juiz (Adrian, 1959, p. 449458; Wright, 2008, p. 13-16). De certa forma, estas tentativas de não depender de partidos para a seleção de canditados contesta o dito por LA PALOMBARA, ainda que se deva considerar que estes modelos alternativos foram implantados em localidades de baixa ou média magnitude, mas de menor extensão territorial, favorecendo inclusive a promoção de uma democracia mais direta e menos representativa. A diminuição da complexidade certamente contribui para a exclusão das organizações partidárias deste sistema.

A concepção de essencialidade que cobre aos partidos se estende por muitos autores, destacando que, em um Estado democrático, as agremiações partidárias são um dos pilares principais e uma condição necessária para a sua existência. Acrescente-se a idéia de alguns doutrinadores de que os partidos são, per se, suficientes para a existência de um regime democrático (Sospedra, 1996, p. 23; Katz e Crotty, 2006a, p. 1) e que a sua relevância não se limita à vida política, indo além, atingindo a vida social (Cotarelo, 1985, p. 12). Se os partidos são os porta-vozes dos interesses vindos de grupos sociais, bem como na sua defesa, por mais que tal tarefa não seja exclusiva destas organizacões, é inegável o seu protagonismo e a sua relevância dentro desta dinâmica. Aqui se poderia indagar, inclusive, se os movimentos sociais mais relevantes na atualidade têm possibilidade de sobreviver sem a sua institucionalização por meio de um partido, ou a sua transformação em um, como ocorreu com o movimento 15M, ou dos indignados, na Espanha.

As tarefas de organização dos interesses sociais e da manifestação e expressão da vontade popular realizadas pelos partidos também são frisadas pela doutrina. É notório que as organizações partidárias identificam interesses, unem cidadãos com as mesmas visões e objetivos, como também canalizam a expressão popular manifestada por meio do voto nas instituições públicas. O exercício de tais funções é fundamental para o devido 
funcionamento da democracia nas sociedades complexas de massa. Estes grupos surgiram justamente para isso, ou seja, para agregar as demandas populares e conduzí-las à arena pública, bem como estiveram presentes na grande maioria dos países do globo, sendo que, em alguns casos, não seria possível pensar em uma democracia sem esta organização de interesses que os partidos proporcionam. O governo, entendido como um conjunto de indivíduos que exercem o poder político e que determinam a direção política de uma sociedade (Bobbio, Matteucci e Pasquino, 2010, p. 553) é capitaneado pelos partidos em muitas democracias modernas, formando o que se denomina como "governo de partidos", algo extensamente aceito pelos Estados atuais e reconhecido pelo exercício de múltiplas funções, como a autorização de dirigir o curso da política (White, 2006, p. 7-8; Scarrow, 2006, p. 16). Os políticos que ocupam o governo vêm dos partidos, passam pelo filtro político destas organizações sendo, muitas vezes, orientados segundo as diretrizes partidárias. Isso é tido como algo normal nas democracias, naturalizando a presença - em muitos casos, obrigatória - dos partidos nas esferas de poder, mas sem o deslocamento deste espaço para outro.

Partindo do presssuposto deste perfil dos partidos como grupos vitais, indispensáveis e necessários para o processo político, e que o próprio "poder" dentro do Estado está nos partidos, surgiu o fenômeno da "partidocracia", para substituir um tipo de democracia mais clássico (Sartori, 1962, p. 136). Este conceito reflete a exarcebação da presença da estrutura burocrática dos partidos na democracia que, de certa forma deixa de ser "do povo" e passa para dos partidos. O embate, neste caso, não é entre os cidadãos, a fim de eleger seus govenantes, mas sim dos partidos, que lutam entre si para eleger as suas elites. É uma degeneração da democracia que coloca as elites partidárias no centro do conflito político, ou seja, que as oligarquias partidárias assumem a soberania, em detrimento do povo (Bueno, 2004). Em um primeiro momento, este termo "partidocracia" não tinha uma conotação negativa, mas sim o sentido de um fato originado a partir do reconhecimento dos partidos na Europa pós-guerra. Por ser um resultado direto do direito de associação, os partidos facilitam a expressão política em larga escala. Deste modo, pode-se entender que, sem eles, não seria possível que o povo expressasse sua vontade (Sartori, 1962, p. 255). No entanto, a ideia de "partidocracia" vem colaborando para a rejeição dos partidos nas democracias, quando os cidadãos entendem que a democracia foi cooptada pelas estruturas partidárias e sua elite, distante da sociedade e cínica diante dos problemas sociais.

Por outro lado, a função de canalização da expressão da vontade popular nas democracias modernas é difusamente utilizada para a defesa dos partidos. Desde os autores mais clássicos como Maurice DUVERGER, os partidos são dotados de um duplo papel na representação política, já que enquadram lado a lado os eleitores - ou representados - e os eleitos, ou representantes (Duverger, 1980, p. 89). Trata-se de um ponto no qual se concentram argumentos a favor dos partidos, mas que também despertam seu questionamento pois, como se sabe, a própria teoria da representatividade sofre uma crise nas democracias atuais, como será abordado mais 
adiante.

O enfoque da representatividade aponta outros fatores que devem ser levados em conta no momento de avaliar a real necessidade dos partidos. Considerando sistemas duais de representação, compostos por organizações políticas que representam a grupos de interesses e partidos, é evidente que as organizações partidárias desempenham um forte papel nestes sistemas. Uma questão diversa é o cumprimento, a execução das funções que lhes foram atribuídas. A distancia entre o eleitorado e tais formações políticas é comumente justificada pelas falhas dos próprios partidos em oferecer uma imagem de si mesmos aos eleitores, como também suas próprias deficiências em atuar democraticamente e de maneira responsável dentro de um sistema que deveria ser pluralista. Se for assim, de igual maneira pode-se afirmar que os partidos realizam as funções que lhes foram conferidas, ainda que de modo imperfeito ou ineficiente. Tais agremiações já mostraram que têm certa tendência à autocorreção, ainda que em muitos casos esta reação demore para acontecer. Entretanto, ainda que tenham esta avaliação negativa, parece não existir uma clara alternativa aos partidos que tenha sido desenvolvida ou cogitada, o que leva a alguns autores a defender a sua permanência e aceitação, com todos os seus defeitos, justamente devido a esta ausência de opções (Ryden, 1995, p. 116-125).

As imperfeições na representação da sociedade por parte dos partidos, refletidas na distância destas organizações após as eleições, no desvio de agendas políticas depois de ter os representantes eleitos, ou mesmo na má seleção de candidatos, fazendo com que o eleitorado opte por algumas estratégias de voto (votar no "menos pior", ou votar "para o outro não ganhar") são trazidas ao debate devido aos problemas teóricos e constitucionais provocados por um eventual monopólio da função de representação popular frente às instituições do Estado. $\mathrm{O}$ partido, como possuidor da exclusividade da representatividade, coloca em xeque a própria teoria da representação nas sociedades modernas e, se a tarefa de representar a cada vertente da sociedade já escapa do alcance de qualquer um, ao menos os partidos realizam esta tarefa e acabam decidindo o que deve ser representado e de que modo (Sartori, 2005, p. 274-275). Sem um nível mínimo de seleção, a própria democracia se vê inviabilizada, já que o conflito de interesses é saudável no meio político, mas um alto grau de conflictividade de interesses não é aconselhável para uma democracia funcional (Diamond, 1999, p. 64-77). Exemplo disso é o longo e não terminado debate sobre qual é o número de partidos representados no Parlamento e que permite garantir a estabilidade do governo, bem como a implementação de medidas necessárias para o normal desenvolvimento do Estado e da sociedade.

Contudo, no que se refere à representação deste pluralismo social por parte dos partidos, o real cumprimento desta tarefa (se é que é possível), como também o limite numérico da presença destas correntes na arena pública para que não se origine um conflito de inviável solução, cabe recordar as lições de Chantal MOUFFE. Ao analisar o cenário político esta autora explicita, a partir de Carl Schmitt, que a característica mais 
marcante do político é o estabelecimento de uma fronteira entre o nós e o eles, sendo a política sempre uma arena de conflito e de antagonismo. A partir dessa perspectiva, MOUFFE diferencia o antagonismo do agonismo. $\mathrm{O}$ antagonismo pressupõe o reconhecimento do outro como inimigo, admitindo-se até mesmo a possibilidade de sua eliminação física. Já o agonismo reflete a luta entre adversários em um cenário democrático e plural, mas mesmo esta luta agonística teria limites. Estabelecer esses limites é uma das tarefas mais difíceis da política democrática, eis que esse momento de fechamento pode comprometer o próprio significado do pluralismo e a seleção de quais lutas devem ser reconhecidas como legítimas na arena política (Mouffe, 2014, p. 14-32). Neste sentido, o pluralismo - entendido como algo impossível de ser traduzido em sua totalidade pelos partidos ou por qualquer outra organização - resta como uma mera valoração da multiplicidade social reconhecida e não negada ou ignorada, o que, de forma alguma, compromete a reputação dos partidos na tentativa de corporizar este complexo plural.

Embora se entenda que tampouco se deve sobrevalorizar a importância dos partidos na mobilização da sociedade e na participação política dos cidadãos, uma vez que a questão da participação também está conectada a diversos outros aspectos que vão além dos partidos em si, é fato que o nível dessa participação é um bom indicador da saúde e vitalidade da própria democracia (Karp e Banducci, 2007, p. 229). E a participação política dos cidadãos que pode ser diretamente alterada pela atuação dessas organizações, pela sua percepção pela sociedade, ou até mesmo no modo como a seleção de candidatos é realizada. Sem dúvida, trata-se de um contexto instrumental dos partidos, pois uma vez que as eleições são centrais nos processos democráticos e que os partidos têm o protagonismo neste processo, eles também colaboram na organização da complexidade da política, agregando informações a um sistema de confiança política e de avaliação do fenômeno político (Dalton e Welson, 2007b, p. 192). Novamente depara-se com a percepção da representatividade das demandas sociais no Estado pois partidos atuantes e que envolvem a mobilização social fazem com que os cidadãos se sintam capazes de alterar a ordem vigente, que sintam que o voto tem o condão de premiar e castigar os que exercem cargos políticos. No entanto, este debate deve ser também de qualidade da democracia, ${ }^{4}$ e não somente dos partidos.

\footnotetext{
${ }^{4}$ A qualidade da democracia é um conceito complexo, porém essencial ao tema ora exposto. Reporta-se ao grau em que, dentro de um regime democrático, uma convivência política se aproxima das aspirações democráticas da sua cidadania. Esta definição pode ser fracionada em cinco elementos: (i) grau de aproximação, que se relaciona com a capacidade da cidadania em desenvolver certos tipos de práticas consideradas desejáveis na gestão de assuntos públicos; (ii) regime democrático, que se conecta diretamente com a ideia de poliarquia de Dahl (Dahl, 2002); (iii) convivência política, que aponta para a relação entre a cidadania e seus líderes, funcionários públicos, bem como os "não-cidadãos", como estrangeiros e crianças; (iv) aspirações democráticas, que reflete o que se considera desejável pelos cidadãos; e (v) cidadania, que é definida pela Constituição mas que, em seu sentido amplo, refere-se ao que é universal (Cullell, 2000, p. 109-121). Este conceito permite entender a democracia não só como um conjunto institucional, mas também como uma vida política, uma experiência cidadã em diversos âmbitos desta convivência política. Sabe-se que muitos cidadãos não vivem a democracia nem em seus níveis medianos, e sendo ciente disso que a qualidade da democracia possibilita distinguir, dentro de um mesmo regime político, os seus pontos fortes e fracos, as boas e as más práticas, se há medidas que aproximam os cidadãos da democracia e que viabilizam canais de accountability, ou se existe o predomínio de condutas clientelistas, autoritárias (Valverde, 2008, p. 109).
} 
Neste contexto, não se ignora o papel do sistema eleitoral em vigor, já que partidos atuantes podem ser prejudicados pelas regras do jogo que distorcem a ideia do one man, one vote, ainda que se possa argumentar que, na maioria das vezes, são os próprios partidos que elegem o sistema eleitoral a ser aplicado.

A indispensabilidade dos partidos pode ser defendida mesmo que não se saiba com precisão como eles identificam e articulam as divisões sociais, ou mesmo se são bem-sucedidos nestas tarefas, quando se enfoca a questão da abertura imprudente do sistema político, que gera fragmentação e instabilidade. Além disto, pode-se inclusive conectar o êxito da consolidação da democracia de um dado país à efetividade dos partidos em estruturar os conflitos políticos existentes (McAllister e White, 2007, p. 211). O mesmo raciocínio pode ser utilizado nos mecanismos de democracia direta, uma vez que os partidos também são atores importantes na promoção das campanhas por referendum, por exemplo (Bowler e Donovan, 2006, p. 665), embora nestes casos se verifiquem muito mais a atuação de grupos sociais mobilizados politicamente. No entanto, cabe a ressalva que esta defesa pode refletir uma posição favorável aos partidos a todo custo, livrando-os do esforço de melhorar o seu desempenho e a qualidade no cumprimento de suas funções. Não parece, assim, que esta defesa seja a mais adequada desde o ponto de vista da qualidade da democracia.

\section{OS ARGUMENTOS CONTRA OS PARTIDOS POLÍTICOS}

A ausência de consenso em torno dos partidos, ainda que histórica, parece estar mais evidente hoje em dia. Em sua face negativa, o raciocínio que vai contra os partidos levanta a hipótese do seu declínio, ou mesmo da sua decadência (Castaño e Toribio, 2002; Montero e Gunther, 2007, p. 18-22).

Existe uma imagem dos partidos como a de uma organização politicamente incorreta, que penetra nas instituições de maneira abrupta e que acaba por corromper o próprio sistema democrático. Isto compreende também grupos políticos relevantes em uma sociedade e que exercem função de representação informal dos cidadãos (como podem ser os grupos de interesses, os meios de comunicação, os líderes independentes) e que terminam sendo bloqueados na sua atuação pelos partidos (Stokes, 1997, p. 2).

As críticas usualmente produzidas pela doutrina partem da noção de governo de partidos (ou seja, um governo orientado pelos partidos, mas ainda dentro da esfera de governo, do Parlamento), em direção ao que se denominou de Estado de partidos (García Pelayo, 1991), em uma clara substituição do Parlamento, tradicional espaço para a tomada de decisões, para as sedes dos partidos ou mesmo para os grupos partidários compostos dentro do Parlamento, cooptando-o; até a transitoriedade dos partidos na história política mundial e a sua transformação em grupos que atuam como forças de mercado e que perderam as suas virtudes, antes tão celebradas. O Estado de partidos, em seu sentido negativo, seria o reflexo de como as elites políticas utilizam os partidos para seus interesses privados, camuflados como ideologias. Também seria a idéia de que os partidos, 
antes instrumentos de representação dos cidadãos, tornaram-se barreiras para o acesso dos indivíduos ao Estado e da reivindicação dos interesses gerais. A partir disto, os partidos perderam as suas características mais importantes para a democracia, acabando por alimentar ainda mais a desconfiança social contra eles mesmos (Daalder, 2007, p. 51-63; Torcal, Montero e Gunther, 2007, p. 247). Isto também se conecta com a crise de representatividade já citada.

Este panorama colide com a democracia de partidos. No Estado de partidos, o Parlamento se descaracteriza como a "casa do povo" para se tornar uma "casa de partidos", deslocando informalmente a esfera de tomada de decisões para as estruturas partidárias. Na democracia de partidos, esta esfera continua sendo no Parlamento e o embate se faz nos debates livres produzidos nas sessões legislativas. Os representantes eleitos pelo voto popular, porém selecionados pelos partidos devendo, portanto, seguirem as suas diretrizes, travam as discussões pautados pela agenda política pela qual foram escolhidos pela população (Chueca Rodríguez, 1988, p. 32-33). Parece possível afirmar que o Estado de partidos é uma degeneração da democracia de partidos, produzida, quiçá, por eles mesmos, já que o detentor do poder tende a abusar dele, utilizando das lições de Montesquieu (2004, p. 166).

Há outras vertentes que entendem que o sistema de partidos deixou de ser suficiente para canalizar a forma de participação política das massas frente ao capitalismo. Fatores como o surgimento dos movimentos sociais que buscam resgatar a identidade dos indivíduos e que têm uma concepção "negativa" da política partidária indicam que os interesses da sociedade deveriam ser perseguidos sem a intervenção estatal, e isto afeta diretamente os partidos, o que leva a buscar alternativas a eles. Seria como se, a partir do declínio do sistema de partidos frente ao capitalismo, o surgimento de formas menos limitadas e reguladas de participação política pudesse resultar em algo benéfico, para compatibilizar os pressupostos institucionais da forma capitalista de organização social e econômica com as demandas políticas vindas da sociedade (Offe, 1988, p. 67-70). Neste sentido, não se pode deixar de citar a posição de Hannah ARENDT, que idealizou, dentro da sua concepção de consenso e de espaço público, um tipo de organização política alternativa ao sistema representativo, em uma clara postura crítica frente aos partidos. A autora propõe substituir os partidos por conselhos que, segundo o seu ponto de vista, seriam mais adequados para a tomada de decisões, facilitando consensos e diminuindo ao máximo o conflito de demandas (Arendt, 1969, p. 233).

No entanto, ARENDT propunha um modelo que conciliasse a democracia representativa e direta, fundamentando uma posição rumo à democracia participativa, que não exclui totalmente os partidos, mas que aumenta os canais de participação. Não foi o caso de Michael HARDT, Antonio NEGRI e Paolo VIRNO. Tais autores pregaram o êxodo do Estado e das instituições políticas tradicionais (como os partidos), como também um rechaço direto da democracia representativa. HARDT e NEGRI reclamam uma ruptura com a modernidade 
e a elaboração de um enfoque diferente, que por sua vez se faz necessário devido às transformações cruciais que as sociedades sofreram desde as últimas décadas do século XX, como a nova percepção do que seja soberania, a evolução do modo capitalista e da passagem da "sociedade disciplinar" para uma "sociedade de controle". Assim, o trabalhador deixa de ser individual e se torna coletivo, o que os autores denominam de "multidão". Esta multidão e seu modo de interação conduzem a um novo tipo de governança, que permite formas de subjetividade mais autônomas e independentes, que podem ser expressas com liberdade e que colaborarão à formação de um novo conjunto de relações sociais que - segundo eles - substituirá o sistema capitalista e implantará uma "democracia absoluta" (HARDT e NEGRI, 2000; 2004). Já VIRNO parte de uma visão menos otimista no que tange ao sucesso da democracia absoluta por parte da multidão, e aborda o êxodo e a desobediencia civil como tipos de sua ação política, esta sim transformada e não conformada mais como antes, a partir do desenvolvimento de uma esfera pública não-estatal e um tipo extremamente novo de democracia, fundamentando-se em formas não representativas e extra-parlamentares de democracia por meio de conselhos, por exemplo (Virno, 2004).

Em ambos os casos, os autores advogam uma democracia da multidão, negando a democracia representativa e identificando nitidamente o que é a multidão e o que é o povo. O povo, nesta linha, é considerado individualmente, como uma vontade única sempre conectada ao Estado (Rousseau, 1980, p. 15 e ss.), algo que se contrapõe à multidão, que recusa a unidade política e impõe uma multiplicidade singular que não pode ser representada por um único canal. A multidão é como um ator auto-organizado que não poderá ser convertido em uma vontade geral, sendo, assim, antiestatal. A democracia da multidão, deste modo, não admite uma autoridade soberana representativa do povo, necessitando de novas formas não representativas de democracia que não incluem os partidos políticos. Contudo, ainda que desde o ponto de vista democrático este cenário seja o ideal, ele pode não ser factível, tendo em vista uma sociedade complexa de massa como a moderna, bem como a própria pulverização de demandas sociais. Entende-se que a universalização da representação política faz com que desapareçam minorias e termina se tornando uma democracia aparente e formal. No entanto, também não se pode levar ao extremo a participação de todos os segmentos sociais, sob o risco de inviabilizar qualquer tipo de representação ou tomada de decisão. Deve-se, talvez, optar por um caminho que otimize e que compatibilize a forte pressão das demandas sociais que precisam ser representadas com as possibilidades reais de realização do ideal democrático. Parece que os partidos, nesta tarefa de otimização, podem ser mais aliados do que efetivamente inimigos.

Já sob o enfoque da democracia participativa, os partidos também são questionados como mecanismos efetivos do alcance dos objetivos de tal modelo. Parece adequado que a democracia, em si mesma, não seja reduzida a um modelo, porque corresponde a um processo que tem formas plurais, composto por condutas complexas e até mesmo paradoxais. É notório que o voto geralmente emitido é motivado muito mais por 
sentimentos do que por "cálculos de interesses programáticos", e isto demonstra que uma parte da sociedade não aceita a lógica do "autoposicionamento ideológico" quando não a tem, sendo tal situação diretamente influida pela confusão ideológica tanto dos partidos, quanto dos seus líderes (Villasante, 1995, p. 121-128). Neste sentido, pode-se dizer que os partidos políticos falham em suas principais funções, que é a de canalizar posições ideológicas ou interesses de grupos sociais, mas que isso pode não se dever somente a eles, mas também à própria sociedade que já rejeita se posicionar ideologicamente, ao menos abertamente, sendo mais volátil em suas demandas.

De fato, esta questão vai mais além da perda de ideologias por parte dos partidos e seus líderes. Por mais que o sufrágio seja universal, não se pode ter certeza da forma como este direito é utilizado, podendo não ser exatamente um problema com os partidos e esta perda de posicionamento ideológico. Os indivíduos, de maneira secreta (o que gera uma individualização de responsabilidades), confiam a sua representação a outros indivíduos (outorgando esta responsabilidade a uma elite), que estará restringida a alguns profissionais até as seguintes eleições (o que seria o tecnicismo do controle). ${ }^{5}$ Quiçá não seja possível reduzir as ideologias aos partidos, uma vez que a democracia deve atender a certo equilíbrio de poderes entre os legitimados pelos votos, os legitimados pelas iniciativas de base e os legitimados pelos conhecimentos profissionais. Parte de tal dinâmica é obstruída pelos partidos, principalmente o acesso dos indivíduos através de tais organizações, quando não estão dotadas de democracia interna, como frequentemente ocorre (Villasante, 1995, p. 145-147).

Isto conduz o debate para além das mudanças das características partidárias sofridas nos últimos anos, levando ao questionamento da sua existência propriamente dita. Frente a problemas de legitimação e de representatividade, atualmente parece que somente os partidos podem operar o sistema com a legitimidade necessária. Além disto, ainda que outros tipos de organizações tenham tentado atuar politicamente no lugar dos partidos, o fato é que nenhuma delas obteve êxito (Yanai, 1999, p. 6-11).

\section{PARTIDOS POLÍTICOS: VÍTIMAS DELES MESMOS?}

Os partidos estão enraizados de tal forma nas democracias ocidentais modernas que não se trata unicamente de expulsá-los da dinâmica política e substituí-los por outros modelos alternativos. É difícil imaginar uma maneira de conduzir a política sem que seja através dos partidos, sendo as dificuldades históricas para suprimi-los um indicador de quão central eles são no governo dos Estados (Ware, 1995, p. 1).

Um mundo em evolução foi provocando novas mudanças e, em último termo, a aparição de um novo Estado, o de bem-estar, que por sua vez ocasionou fortes impactos na vida política e no seu funcionamento no período pós-guerra. O sufrágio universal já consolidado motivaria a criação de novas tecnologias que pretendiam

\footnotetext{
${ }^{5}$ Também há a questão de entender qual é o tipo de mandato se outorga para a representação que se deseja ou que é possivel em uma democracia moderna. Para tanto, cf. Pitkin, 1985.
} 
chegar à maior quantidade de eleitores através de uma campanha centrada nos instrumentos audiovisuais. Esta nova forma de propaganda eleitoral substituiu as estratégias anteriormente usadas pelos partidos de massas, ${ }^{6}$ afetando diretamente a militância e privilegiando o impacto mediático em detrimento desta mobilização. Junto a isto, o aporte de recursos públicos passou a ser fundamental para a própria vida política dos partidos, sendo necessário o maior número possível de eleitores para a sua obtenção. Assim, a lógica obrigava aos partidos a fazer política a partir de uma determinada ideologia mais flexível, facilitando o convencimento e a captação de votantes e abandonando os eventuais radicalismos antes constantes e que porventura foram o motivo do surgimento da sigla. Terminou-se por criar, assim, juntamente com outras razões, outro tipo dominante de partido político que, na conhecida denominação de KIRCHHEIMER, seriam os partidos "catch-all" (Kirchheimer, 1980, p. 328-347).7

Um dos efeitos mais visíveis deste tipo de partidos se percebe no âmbito da participação partidária, que se converte em meramente simbólica, privilegiando a impermeabilidade e a imobilidade da elite dentro da organização. O próprio militante "tipo" com forte identificação ideológica termina desapreciado na estrutura real de poder que, em virtude da "transversalidade" que garante o êxito eleitoral, acaba reduzindo a vida política à estrita relação entre a elite do partido e os eleitores. O financiamento de tais organizações também se vê alterado, já que as elites têm a seu favor o controle real dos numerosos recursos públicos - resultantes do desempenho eleitoral - diminuindo assim a importância da filiação e da sua base social, o que paralelamente marginaliza as contribuições por meio das quotas de filiados. Conjuntamente, as fontes disponíveis de arrecadação de fundos econômicos também decrescem, fazendo com que surjam outras opções que talvez não atendam aos princípios democráticos, como pode ser o financiamento irregular, a influência dos grupos de pressão, ou mesmo o significativo aumento do financiamento público sem considerar um eventual fechamento do sistema de partidos ou o rechaço da opinião pública, já significativamente influenciada pelo descontentamento da atuação partidária na democracia (Santano, 2014).

Justo no começo desta mutação dos partidos de massas para os partidos “catch-all”, já se apresentavam opiniões que refletiam o seu paradoxo, uma vez que eram elementos essenciais à democracia, mas que, por outro

\footnotetext{
${ }^{6}$ Adota-se o conceito de Bobbio, Matteucci e Pasquino de partidos de massas. Refere-se "a partidos com uma organiação difusa, estável, com um corpo de funcionários pagos especialmente para desenvolver uma atividade política e um programa político. (...) Uma estrutura partidária articulada, capaz de enfrentar uma uma ação política contínua que envolvesse o maior número possível de trabalhadores e que atingisse todas as esferas da vida sócia, que acolhesse suas demandas e exigências específicas e as transformasse num programa geral" (2010, p. 900).

${ }^{7}$ Para a definição dos partidos catch-all, também se utilizará da lição de Bobbio, Matteucci e Pasquino: "diferentemente dos partidos dos trabalhadores [de massa], estes partidos [que os autores chamam de eleitoral de massa, como sinônimo de catch-all] tiveram e têm como característica distintiva a mobilização dos eleitores mais do que a dos associados. Dotados de uma organização em parte decalcada sobre a dos operários - como seções, federações, direção centralizada e pessoal político trabalhando em tempo integral - os partidos eleitorais de massa não são dirigidos de um modo geral a uma classe ou a uma categoria particular, não se propõe uma gestão diferente da sociedade e do poder, mas procuram conquistar a confiança dos estratos mais diversos da população, propondo plataformas amplas e flexíveis, além de suficientemente vagas, a satisfação do maior número de pedidos e a solução dos mais diversos problemas sociais". (2010, p. 901-902).
} 
lado, terminavam violando muitos dos preceitos que a própria democracia lhes impunha. Neste sentido, os partidos não estavam sendo leais à democracia, sistema este que foi o maior responsável pela sua manutenção e permanência na arena política (Neumann, 1957, p. 12-13). Na verdade, trata-se de uma ambigüidade um tanto complicada para explicar aos cidadãos comuns na sociedade e que termina sendo interpretada sempre contra as agremiações partidárias, gerando efeitos diretos sobre os indivíduos. ${ }^{8}$

Especula-se que a próxima fase da evolução dos partidos é o comportamento tipo "cartel". Isso se verifica quando existe uma interpenetração dos partidos no Estado, acompanhada de um padrão de coalizão entre as organizações que integram o "cartel". Ainda que sejam rivais aparentemente, acabam se ajudando mutuamente para o mesmo resultado, manejando melhor uma possível competição eleitoral, inclusive pela independência de seus líderes em relação à frágil militância existente (Katz e Mair, 2004. p. 26 e ss.). Não parece que esta seja somente uma suposição, quando se verifica esta mútua colaboração na realidade, como pode ser o caso brasileiro.

O distanciamento dos programas partidários ou propostas eleitorais da sua base militante; a perda muitas vezes irrecuperável - da ideologia que originou a sua organização como estrutura; a preferência por estratégias partidárias de simples captação de votos, que freqüentemente nem sequer são fiéis em duas eleições consecutivas; a utilização de tais formações políticas como "ponte" ao poder, sem ter em conta, pelo menos, um nível razoável de accountability ou demandas coletivas, verdadeiro objeto dos partidos frente ao Estado, são somente alguns motivos que conduzem a opinião pública à descrença, à desconfiança, e inclusive ao rechaço dos partidos. As necessidades sociais que não estão sendo satisfeitas por meio deles estão sendo reconduzidas a outros grupos e associações formados pela sociedade civil, refletindo de alguma forma a função de canalização das petições populares até o Estado. Tal fenômeno não é algo novo e também apresenta características de irreversibilidade, embora ainda se coloque em dúvida se estes movimentos têm capacidade de perdurar no tempo quando optam por não se institucionalizarem e por não usar os meios tradicionais de participação política.

Os problemas surgem quando existe certa "impaciência" na busca de alternativas, ou mesmo com a aplicação de medidas pouco reflexivas, promovendo uma situação adequada para que atores pouco indicados exerçam as tarefas que os partidos não logram realizar. Exemplo disto são os meios de comunicação, grandes responsáveis do advento de "inimigos" dos partidos, abordando a questão a partir de opiniões de pessoas não especialistas em política e que influenciam diretamente na percepção deste fenômeno por parte dos indivíduos.

\footnotetext{
${ }^{8}$ É interessante destacar a comparação da teoria do partido burocrático de massas para o profissional eleitoral de Panebianco com a teoria de Kirchheimer. Panebianco expõe em termos mais claros que o modelo que sucede aos partidos de massas conta, basicamente, com a especialização das eleições, dos nichos eleitorais e dos aportes econômicos para as campanhas eleitorais vindos desde o Estado. O autor, assim, demonstra que Kirchheimer tratava da ideologia dos partidos e a sua relativização, enquanto ele enfocava na parte administrativa de tais agremiações (1982, p. 480 e ss.).
} 
Isto possibilita a aparição de outsiders $^{9}$ que, utilizando-se de uma ferramenta tão poderosa como os meios de comunicação, chegam aos lugares mais esquecidos da sociedade, sem que se necessite de um partido ou de uma ideologia (Castaño e Toribio, 2002, p. 21-22). Isto pode ser ainda mais freqüente quando o sistema eleitoral vigente admite a apresentação de candidaturas individuais, ou quando a criação de partidos é significativamente facilitada. Outra hipótese é a da utilização de ferramentas legítimas de participação política popular no Estado de modo indevido, como podem ser os projetos de iniciativa popular - que claramente se fundamentam em um Estado democrático e devem ser previstos em todos os sistemas assim considerados -, mas que, se usados de maneira que não atende aos valores democráticos ou que possuam objetivos que se sobrepõem ao interesse público, podem induzir em erro os cidadãos que concedem seu apoio, favorecendo causas particulares e clientelistas, pouco condizentes com o que se entende por "democrático".

Diante de tantas conseqüências possíveis e danosas para a democracia, entende-se que a institucionalização política dos partidos políticos é necessária, sendo também um dos principais componentes de qualquer processo democrático bem sucedido (Carbone, 2003, p. 496). Inclusive em contextos de crise do sistema de partidos, os estudiosos da democracia participativa não renunciam a eles, e tampouco provaram substituí-los por outros instrumentos para o aperfeiçoamento da democracia, o que permite afirmar que, sem as agremiações partidárias, a democracia pode se ver inviabilizada ou meso não haver (Alcántara Saez, 2009, p. 7682). Existe um processo de desvalorização da política democrática por parte dos cidadãos, gerando por sua vez desconfiança e um sentimento de rejeição ao assunto. Contudo, parece que, mesmo assim, tais efeitos não levam ao abandono das organizações partidárias no sistema democrático (Paramio, 2002, p. 8-12).

Feira a análise das diversas fases do desenvolvimento dos partidos políticos parece que o caminho não é a recusa dos mesmos, mas sim a provocação de sua transformação, adaptando-os aos novos tempos e à nova democracia sobre a qual eles deverão atuar (Mouffe, 2014, p. 85). A própria trajetória das organizações partidárias demonstra a sua capacidade de se moldar segundo as mudanças sociais, até como forma de sobrevivência na esfera política. Logicamente, isso também altera a maneira de como eles exercem as suas funções na democracia, levantando o questionamento se eles estão em crise, ou se o cumprimento das suas funções já se mostra insuficiente no modelo de sociedade atual.

\section{E AS FUNÇÕES ATRIBUÍDAS AOS PARTIDOS?}

Não são somente os partidos em si que devem ser postos à prova quando se questiona o seu papel na democracia. As suas funções também devem ser objeto de análise. Estas consistem, teoricamente, na mobilização

\footnotetext{
${ }^{9}$ Entende-se como um outsider aquele candidato ou agente político que consegue destaque não através dos partidos já estabelecidos, mas como políticos independentes ou mesmo partidos ou associações novas no sistema (Carreras, 2010).
} 
dos grupos sociais e na sua integração no processo democrático, canalizando a sua participação e diminuindo o desinteresse pela política a limites que a democracia não esteja comprometida. Além disto, também corresponde aos partidos a tradução das demandas sociais em programas de governo, com a expectativa de poder concretizálos através dos poderes públicos (García-Pelayo, 1986, p. 75-80). Juntamente com isto, adquire especial relevância hoje em dia a seleção de uma elite política destinada a ocupar os cargos representativos através das eleições. Estas tarefas colocam em relevo o papel das organizações partidárias, que não se limita a constituir o principal vínculo na relação entre o Estado-estrutura e o Estado-comunidade, ou seja, entre a "sociedade política" e a "sociedade civil", mas que engloba a estruturação da comunidade como um único sujeito politicamente atuante, tendo em conta a complexidade sempre presente nas sociedades contemporâneas (Blanco Valdés, 1992, p. 43).

A democracia traz dentro de si a idéia de soberania popular, da liberdade de eleição de uma opção política; de competição igualitária entre os diferentes grupos políticos; da periodicidade no exercício deste poder pelo eleito; pelo partido da situação (Lowenstein, 1979, p. 95) e a possibilidade da sua mudança (Kelsen, 1977, p. 30; Ridola, 1993, p. 2968). É neste ponto que surge a importância do pluralismo político. A essência da democracia constitucional é a participação livre e ilimitada dos mais diversos grupos nos processos políticos e sociais (Lowenstein, 1979, p. 422-424).

A idéia de pluralismo político ganha destaque na teoria democrática da Ciência Política do pós-guerra a partir da análise da influência dos diversos grupos de interesse sobre o processo de tomada de decisões do Poder Executivo. O processo de governo estaria caracterizado por uma ampla pluralidade de grupos de interesse que competem um com o outro no resultado das decisões políticas (García-Pelayo, 1977, p. 204; Wenman, 2008, p. 157). A partir dos anos 60, o pluralismo partidário adquiriu uma nova interpretação e começou a ser visto como a melhor defesa e legitimação do principio majoritário limitado, ou seja, do principio que sustenta que a maioria deve respeitar os direitos da minoria e que deve exercitar seu poder com moderação, até o limite imposto para o respeito a esta pluralidade (Sartori, 1997, p. 482.485). O processo de decisão política somente estaria garantido nos ordenamentos jurídicos democráticos por meio da comum aceitação da diversidade de opiniões e do pluralismo das formações sociais, o que se traduz na formação da vontade popular através de um processo dialético de compensação de forças políticas operando na sociedade. Portanto, o respeito das "regras do jogo" que asseguram a igualdade e a liberdade neste processo permite que, por sua vez, exista a possibilidade da alternância no poder e a tutela do direito de oposição (Ridola, 1982, p. 110).

Contudo, devido a outros fatores do desenho institucional no qual os partidos estão inseridos, pode ser que grande parte destas forças possa a prioricarecer da possibilidade real de obter representação política, afetando a credibilidade da existência de um pluralismo político real, ainda que indiretamente. Mesmo assim, não parece claro, neste ponto, que se possa falar de uma crise dos partidos (Ware, 1998, p. 243), embora se possa mencionar 
problemas na tradução dos votos em cadeiras, no desenho deste sistema eleitoral e que atinge diretamente a possibilidade de um pluralismo real, bem como se esta contenção do pluralismo é necessária para a manutenção da democracia funcional, sacrificando os mais "fracos" na esfera política.

Os partidos políticos também são considerados como instrumentos relevantes na função e manifestação da vontade popular, ao selecionar e permitir canais de comunicação entre a sociedade e o Estado. Esta tarefa é uma das principais das agremiações partidárias, já que devem agrupar a vontade popular para tentar transformá-la na diretriz do governo do Estado, requerendo para isto uma vontade permanente de concorrer às eleições, o que os coloca em uma posição privilegiada na disputa eleitoral.

Pois bem, obviamente os partidos não são os únicos responsáveis na conformação desta vontade popular, como tampouco o pluralismo político se limita somente aos partidos. O que se pode afirmar é que a sua posição na realização desta função é privilegiada, isto é, que entre os atores existentes para exercer tal função de concorrência, formação e manifestação da vontade popular, sem dúvida os partidos são os protagonistas (Grimm, 1996, p. 389; Álvarez Conde, 2005, p. 112).

O problema da vontade popular surge da grande complexidade de vontades individuais de uma sociedade. Sendo os partidos políticos responsáveis principais, mesmo que não exclusivos, da formação e manifestação da vontade popular, convertem-se em instrumento de redução desta complexidade. Entretanto, para que isto esteja em consonância com o conceito de Estado democrático, os partidos devem saber como canalizar este processo e se constituir verdadeiramente em meios de expressão de toda esta pluralidade que possa existir.

A representação política é um dos princípios do Estado democrático e se realiza a partir da eleição dos representantes pelos cidadãos - em uma clara manifestação da vontade popular - tais representantes expressarão as demandas sociais pelas quais foram eleitos, mesmo que representarão toda a sociedade (Bastida Freijedo, 1987, p. 212; Barbera, 2008, p. 854). Assim, a representação política pode ser entendida como um procedimento em que uma determinada classe política é eleita para dirigir as demandas da sociedade aos órgãos e instituições estatais, com o fim de envolvê-los no debate de políticas públicas (Lucas Verdú, 1984, p. 531), resultado do exercício do direito de participação política (Bastida Freijedo, 1987, p. 200 e ss.). A idéia clássica de representação política nos tempos modernos se vê bastante distorcida se for considerada a natural complexidade da sociedade e da ampliação da base eleitoral, permitindo o aumento significativo desta complexidade e dificultando a relação representante-representado (Barbera, 2008, p. 859). Neste sentido, considera-se que os partidos identificam as demandas da sociedade e as representam frente às instituições públicas, seja através do seu papel de governo ou na oposição. Por mais que se saiba que os partidos políticos não tenham o monopólio da representação - como já se 
afirmou - não se pode negar que o seu papel frente ao Estado e à sociedade seja de extrema importância. ${ }^{10}$

Entretanto, desde o momento que se tem a impressão de que o Estado de partidos está se sobrepondo à democracia de partidos, há uma distorção não prevista e esse não parece ser um problema menor, já que o modelo normativo de democracia a partir destas organizações os torna indispensáveis (González Encinar, 1992, p. 30-32; García, 2000, p. 55-59). A intervenção por parte das organizações partidárias na relação Estado-sociedade e a sua consideração como elementos necessários nesta dinâmica lhes têm concedido um nível de influência quiçá maior do que tais sociedades julgam aceitável, desde o ponto de vista da legitimação democrática (Carreras Serra, 2004, p. 113-114; Holgado González, 2006, p. 2697).

Mesmo que existam sistemas nos quais não há o monopólio dos partidos na função de formação e manifestação da vontade popular (em sistemas que admitem alternativas, como iniciativas populares de lei, candidaturas independentes, e outros), não se pode afirmar que as distorções ou que o seu comportamento e sua "localização" no Estado não tenham alcançado níveis muito altos. ${ }^{11}$ Sem mencionar que os partidos seguem sendo esta peça fundamental na relação entre sociedade e Estado, a função de representação exercida por estas organizações vai perdendo qualidade "representativa", o que gera não poucas distorções para uma correta compreensão democrática da soberania popular com um valor atual, ${ }^{12}$ mais além de uma democracia minimalista e "schumpeteriana", somente como procedimento de eleição entre elites capazes de governar (Schumpeter, 1984, p. 346-348; Gomes Canotilho, 1999, p. 1317-1318).

Por outro lado, se a representação é resultado do exercício do direito de sufrágio, e o responsável por instrumentalizar estes votos em cadeiras é o sistema eleitoral (sendo este o seu conceito mais difundido [Nohlen, 1981, p. 81 e ss.]), é notório que não há sistemas eleitorais que não contemplem corretores para chegar ao resultado mais adequado à realidade do país onde se apliquem. No entanto, ainda que justificadas, tais distorções podem favorecer - como costuma ocorrer - aos partidos majoritários (Holgado González, 2006, p. 2692-2693). Desta forma, o processo de tomada de decisões a partir das instituições legislativas também sofrerá as influências deste déficit representativo, fazendo com que existam interesses sociais que fiquem marginalizados ou subrrepresentados (Castillo Vera, 1978, p.153). Os efeitos da combinação dos sistemas que compõem a estrutura política de um Estado dependerão em maior medida de como se maneja a sua interdependência, ou seja, do grau de conexão que um sistema tem com o outro. O que cabe afirmar é que, de todos os modos, esta complexa e "multinível" relação entre sistemas não aperfeiçoa, em muitos casos, o princípio representativo.

\footnotetext{
${ }^{10} \mathrm{Ou}$ seja, a representação política não se esgota nos partidos, ainda que sejam essencialmente através deles. (García Roca, 1999, p. 62-63).

${ }^{11}$ Não se trata de questionar teoricamente o ideal democrático, mas sim de identificar um vazio entre a teoria e a praxis constitucional, que está se preenchendo pela "impostura", que faz com que tal vazio seja suscetível de se converter em uma "completa paródia da realidade”. (García, 2000, p. 59).
} 
Outro ponto não menos importante nesta discussão é o momento que a democracia atravessa atualmente. $\mathrm{O}$ ideal democrático não tem rivais no mundo, embora os regimes que o reivindica suscitem fortes críticas em diversas partes do mundo. A erosão da confiança nos representantes é um problema que vem se acentuando a partir da diminuição da participação cidadã nas urnas e do aumento da mobilização política por vias transversais. A este momento, ROSANVALLON denomina de contrademocracia (Rosanvallon, 2007). A desconfiança política de tipo democrático gera uma sociedade da desconfiança, fragilizada em termos de capital social. Significa dizer que os cidadãos confiam menos uns nos outros, rompendo esta rede mútua de colaboração e debilitando as instituições (Putnam, 1994, p. 167). Diante disso, seria correto afirmar que a existência de desconfiança entre os cidadãos provoca, por sua vez, desconfiança dos cidadãos aos seus governantes, ou seja, desconfiança política (Rosanvallon, 2007, p. 29).

Sendo os partidos políticos agentes destas instituições, obviamente que são alvos quase que automáticos desta desconfiança cidadã. Contudo, este cenário pode ser fomentado negativamente pelo surgimento de uma patologia da democracia eleitoral-representativa já comum em alguns países: o populismo. ${ }^{13} \mathrm{O}$ populismo é um fenômeno que, focando as tensões estruturantes da representação, propõe resolver as dificuldades de representar o povo por meio da sua unidade e homogeneidade, a partir de um modelo imaginário. O discurso populista engloba em sua maioria a um formato maniqueísta, no qual sempre haverá a indicação de um opositor, que pode ser o estrangeiro, a elite, a oligarquia, o inimigo. $O$ populismo radicaliza a democracia de controle, conduzindo a sociedade para a impolítica, a uma contrademocracia absoluta. Com o afã de vigiar e criticar os ocupantes do Estado, o populismo termina estigmatizando de forma compulsiva e permanente as autoridades governantes. Por outro lado, o populismo também afeta a soberania de obstrução, ou seja, mostra-se como uma expressão política de crise que pode ser comparada com os partidos antisistema. Parte da base de um sentimento revolucionário e de rejeição do mundo político (Rosanvallon, 2007, p. 259-262).

Parece que a denominada "crise dos partidos" e o seu expressivo questionamento na arena política é uma consequência, um preço a se pagar, pelo protagonismo conferido a eles na democracia. É um ônus que eles devem suportar, por serem destinatários de tarefas tão pesadas na sociedade.

\section{CONCLUSÃO}

Embora se entenda que há muitos elementos interligados no debate sobre a real necessidade de partidos políticos na democracia moderna, parece que a sua exclusão ou extinção não é uma opção a ser considerada, por

\footnotetext{
${ }^{12}$ Ainda mais se for pensar que a crise dos partidos tem feito com que a representação não seja mais um monopólio parlamentário, mas sim de diversos grupos da sociedade, como os sindicatos e organizações de interesse, entre outros. (Barbera, 2008, p. 885).

${ }^{13}$ Aqui se utiliza o termo populismo europeu, já que Rosanvallon, autor que elaborou o conceito exposto, se refere ao fenômeno percebido no contexto europeu.
} 
seu radicalismo. A dificuldade de se extirpar um canal de participação política de tão longa data, com tanta relevância, bem como a ausência de alternativas viáveis para a sua substituição, levam a crer que é necessário desenvolver meios para que a sociedade civil atue e participe, ou através de mecanismos da democracia direta, ou por meio das associações que tenham canais de acesso ao poder, para além dos partidos. Ainda, é essencial que também se reformulem as bases atuais das organizações partidárias, avaliando até onde se chegará com a sua "transformação", analisando se o resultado responde ao que se deseja de entes tão importantes assim.

A diversificação e melhoria de ferramentas de participação política ativa por parte dos cidadãos podem canalizar melhor o descontentamento presente na sociedade e fortalecer o sentimento e os valores democráticos. Trata-se de uma cadeia na qual se fomenta a geração e o crescimento do capital social entre os cidadãos, despertando a percepção do sentido de cidadania, que consequentemente desembocará nas instituições públicas, incluindo os partidos. O que não se pode permitir é "demonizar" a participação política popular de forma paralela à representação, como forma de proteger os partidos. Tal discurso vem sendo recorrente no Brasil, por exemplo, ${ }^{14}$ e não colaboram em absoluto ao avanço na solução do problema. Aqui novamente valem as lições de MOUFFE, que afirma que, admitindo o conflito e não negando o antagonismo, é possível abandonar a "luta entre inimigos" para converter-se em "luta entre adversários" (Mouffe, 2014, p. 22).

Novamente é certo que os partidos já comprovaram que têm capacidade de adaptação às novas tendências e transformações sociais (Yanai, 1999, p. 14), porém se adaptar é suficiente?

Sabe-se que a democracia não seria o que é se não fosse pela colaboração direta dos partidos. Por sua vez, é notório que os partidos não teriam a importância que têm se não fosse pelo regime democrático. Não se trata de idéias antagônicas, como às vezes pode-se pensar, mas são complementares, do mesmo modo que deve ser interpretada a relação dos partidos com a sociedade civil, que tampouco deve ser excludente. Agregando fatores para melhorar a sistemática política, como também revisando e atualizando a realização das suas funções na democracia contemporânea, é possível reverter este cenário e sepultar de uma vez por todas a expressão "crise dos partidos".

\title{
DEMOCRACY, SOCIETY AND POLITICAL PARTIES: AN APPROACH TO AN EVENTUAL EXISTING OF PARTISAN ORGANIZATIONS' CRISIS
}

\begin{abstract}
${ }^{14}$ Como ocorreu no caso do Decreto 8.243/14, que elaborava e regulamentava a participação de conselhos populares nos órgãos da Administração Pública direta e indireta. Este Decreto foi alvo de uma forte polêmica por parte do Congresso Nacional, que alegou o esvaziamento do Poder Legislativo com a abertura de canais paralelos de tomada de decisões. Este Decreto terminou com a sua eficácia sustada pela Câmara dos Deputados, mas segue com seu trâmite parado no Senado Federal.
\end{abstract}


Political parties' action in society - as its representative in the State- and their instrumental character pose the need or not of their existence in the center of academic and political agenda, in different parts of the world. This paper aims at questioning the existance of such crisis and its extense and consequences to democracy. For, it initially reviews the literature on the theme and then, the main arguments against and pro political parties. Then, it analyses political parties capacities to accomplish their traditional given functions. Finally, it asserts that the crisis is not in the organizational character of political parties but in the misrepresentations of it, mainly in accomplishing their functions.

Keywords: Democracy; political parties; political representation; crisis; public institutions

\section{REFERÊNCIAS BIBLIOGRAFIA}

ADRIAN, C. R. A typology for nonpartisan elections. Political Research Quarterly. v. 12, n² 2, p. 449-458, june, 1959.

ALCANTARA SAEZ, M. Los partidos y la política en América Latina al inicio de 2009. Revista latinoamericana de política comparada. v. 2, jul., p. 71-83, Ecuador, 2009.

ALVAREZ CONDE, E. El Derecho de Partidos. Madrid: Colex, 2005.

ARENDT, H. Thoughts on politics and revolution. Crisis of the republic. New York: Harvest Books, 1969. Disponível em: < http://monoskop.org/images/f/f4/Arendt_Hannah_Crises_of_the_Republic_1969.pdf> Acesso em 08 jan.2015.

BARBERA, A. La Rappresentanza Politica: un Mito in Declinio? Quaderni Costituzionali. Anno XXVIII. no 4, Diciembre, Bologna: Il Mulino, p. 854, 2008.

BASTIDA FREIJEDO, F. Derecho de Participación a través de Representantes y Función Constitucional de los Partidos Políticos. Revista Española de Derecho Constitucional, a. 7, n² 21, sep./dic., p. 199-228, 1987.

BLANCO VALDÉS, R. L. Democracia de Partidos y Democracia en los Partidos. In: GONZÁLEZ ENCINAR, J. J. (coord.) Derecho de Partidos. Madrid: Espasa-Calpe, 1992.p. 41-66.

BOBBIO, N.; MATTEUCCI, N.; PASQUINO, G. Dicionário de política. v. 2, Brasília: UnB, 2010.

BOWLER, S.; DONOVAN, T. Direct democracy and political parties in America. Party Politics, v. 12, no 5, p. 649-669, 2006.

BUENO, G. Panfleto contra la democracia realmente existente. Madrid: La esfera de los libros, 2004.

CARBONE, G. M. Political Parties in a 'no-party'democracy - Hegemony and Opposite under 'movement democracy' in Uganda. Party Politics, v. 9, no 4, p. 485-501, 2003.

CARRERAS, M. The rise of outsides in Latin America, 1980-2010: An institutionalist perspective. Comparative political studies. v. $45, n^{\circ} 12$, p. 1451-1482, 2010. 
CARRERAS SERRA, F. Los Partidos en Nuestra Democracia de Partidos. Revista Española de Derecho Constitucional, año 24, nº 70, ene./abr., p. 91-126, 2004.

CASTAÑO, G. M.; TORIBIO, R. Democracia, Partidos Políticos y Sociedad Civil. Bogotá: Red Interamericana para la Democracia, 2002.

CASTILLO VERA, P. La Campaña del Referéndum Constitucional. Revista de Estudios Políticos. nº 6. Madrid: Centro de Estudios Constitucionales, p.153-174, 1978.

CHUECA RODRIGUEZ, R. L. La representación como possibilidad em el Estado de Partidos. Revista de Derecho Político. n.27-28, p. 23-44, 1988.

COLOMER, J. M. Instituciones Políticas. Barcelona: Ariel, 2001.

COTARELO, R. G. Los Partidos Políticos. Madrid: Sistema, 1985.

CULLELL, J. V. Calidad de la democracia. In: AA.VV. Diccionario electoral. Tomo I. San José de Costa Rica: IIDH/CAPEL, 2000.p. 109-121.

DAALDER, H. ¿Partidos negados, obviados o redundantes? Una Crítica, In: AA.VV. Partidos Políticos: viejos conceptos y nuevos retos. Madrid: Trotta, p. 49-70, 2007.

DAHL, R. La Poliarquía: Participación y Oposición USA: Yale University Press, 2002.

DALTON, R. J.; McALLISTER, I. Political Parties and political development: a new perspective. Party Politics, v. 13, no 2, p. 139-141, 2007a. $2007 \mathrm{~b}$

WELDON, S. Partisanship and party system institutionalizatio. Party Politics, v. 13, no 2, p. 179-196,

DIAMOND, L. Developing Democracy. Maryland: John Hopkins Press, 1999.

DUVERGER, M. Instituciones Políticas y Derecho Constitucional. 6.a ed. Barcelona: Ariel, 1980.

FERNÁNDEZ-MIRANDA CAMPOAMOR, C.; FERNÁNDEZ-MIRANDA CAMPOAMOR, A. F. Sistema Electoral, Partidos Políticos y Parlamento. Madrid: Colex, 2003.

GARCÍA ROCA, J. Cargos Públicos Representativos - Un Estudio del Artículo 23.2 de la Constitución. Pamplona: Aranzadi pp. 62-63, 1999.

GARCÍA, E. El Estado Constitucional ante su 'Momento Maquiavélico'. Madrid: Civitas, 2000.

GARCÍA-PELAYO, M. Las Transformaciones del Estado Contemporáneo. Madrid: Alianza, 1977.

El Estado de Partidos. In: Obras Completas II, Madrid: Centro de Estudios Constitucionales, p. 19692078, 1991 .

GOMES CANOTILHO, J.J. Direito Constitucional e Teoria da Constituição. $3^{\circ}$ ed. reimp. Coimbra: Almedina, 1999. 
GONZÁLEZ ENCINAR, J. J. Democracia de Partidos “versus” Estado de Partidos. In: GONZÁLEZ ENCINAR, J.J. (coord.), Derecho de Partidos. Madrid: Espasa-Calpe, p. 17-39, 1992.

GRIMM, D. Los Partidos Políticos. In: BENDA, E.; et al, Manual de Derecho Constitucional. Madrid: Marcial Pons, p. 389-444, 1996.

HARDT, M.; NEGRI, A. Empire. Cambridge: Harvard University Press, 2000. Disponível em: < http://www.angelfire.com/cantina/negri/HAREMI_printable.pdf> Acesso em 08 jan.2015.

Multitude. War and democracy in the age of empire. New York: Penguin Press, 2004. Disponível em: < http://rebels-library.org/files/multitude.pdf> Acesso em 08 jan.2015.

HOLGADO GONZÁLEZ, M. Partidos y Representación Política. In: AA.VV. Derecho Constitucional para el Siglo XXI - Actas del VIII Congreso Iberoamericano de Derecho Constitucional, Tomo II, Sevilla: Thompson Aranzadi, pp. 2691-2701, 2006. http://ec.europa.eu/public_opinion/archives/eb/eb74/eb74_publ_en.pdf. Acesso em 24 abr.2014. http://www.transparency.org/gcb2013/country/?country=brazil. Acesso em 08 jan.2015.

KARP, J. A.; BANDUCCI, S. A. Party Mobilization and political participation in new and old democracies. Party Politics, v. 13, n²,pp. 217-234, 2007.

KATZ, R. S.; MAIR, P. Changing Models of Party Organization and Party Democracy: The Emergence of the Cartel Party. Party Politics, v. 1, no 1, pp. 5-28, 1995.

El Partido Cartel: La Transformación de los Modelos de Partidos y de la Democracia de Partidos. Zona Abierta. no 108-109, p. 9-42. 2004

Party in democratic theory. In: AA.VV.: Handbook of party politics. Great Britain: Sage, p. 34-46, 2006a. CROTTY, W. Introduction. In: AA.VV.: Handbook of party politics. Great Britain: Sage, p. 1-4, $2006 \mathrm{~b}$.

KELSEN, H. Esencia y Valor de la Democracia. 2ºd, Barcelona: Guadarrama, 1977.

KIRCHHEIMER, O. El Camino Hacia el Partido de Todo el Mundo. In: LENK, K.; NEUMANN, F. (eds.), Teoría y Sociología Críticas de los Partidos Políticos. Barcelona: Anagrama, p. 328-347, 1980.

LA PALOMBARA, J. Reflections on political parties and political development, four decades later. Party Politics, v. $13, n^{\circ} 2$, p. 141-154, 2007

LINZ, J. J. Conclusiones: Los Partidos Políticos en la política democrática, problemas y paradojas. In: AA.VV. Partidos Políticos: viejos conceptos y nuevos retos. Madrid: Trotta, p. 277- 306, 2007.

LIPOVETSKY, G.: La era del vacío. Ensayos sobre el individualismo contemporáneo. Barcelona: Anagrama, 1986.

LOWENSTEIN, K. Teoría de la Constitución. 2º ed., reimp. Barcelona: Ariel, 1979.

LUCAS VERDÚ, P. Curso de Derecho Constitucional. Vol. IV, Constitución Española de 1978 y Transformación Político-Social Española. Madrid: Tecnos, 1984.

MAINWARING, S.; SCULLY, T. R. Building Democratic Institutions: Party Systems in Latin America. Stanford: Stanford University Press, 1995. 
McALLISTER, I., WHITE, S. Political parties and democratic consolidation in post-communist societies. Party Politics, v. 13, n², p. 197-216, 2007.

MICHELS, R. Los Partidos Políticos I. Buenos Aires: Amorrortu, 1996.

MONTERO, J. R.; GUNTHER, R. Introducción: Los Estudios sobre los Partidos Políticos. In: AA.VV., Partidos Políticos: viejos conceptos y nuevos retos. Madrid: Trotta, p. 15-48, 2007.

MONTESQUIEU, Charles Louis de Sécondat. Do espírito das leis. Tradução de Jean Melville, São Paulo: Martin Claret, 2004.

MOUFFE, C. Agonística - pensar el mundo políticamente. Buenos Aires: Fondo de Cultura Económica, 2014.

NEUMANN, F. Approaches to the study of Political Power: The Democratic and the Authoritarian State. USA: Free Press, 1957.

NOHLEN, D. Sistemas Electorales del Mundo. Madrid: Centro de Estudios Constitucionales, 1981.

OFFE, C. Partidos Políticos y nuevos movimientos sociales. Madrid: Sistema, 1988.

OSTROGORSKI, M. La Democracia y los Partidos Políticos. Madrid: Trotta, 2008.

PANEBIANCO, A. Modelli di Partiti: Organizzazione e Potere nei Partiti Politici. Bologna: Il Mulino, 1982.

PARAMIO, L. Reforma del Estado y Desconfianza Política. Lisboa: CLAD, 2002.

PITKIN, Hannah Fenichel. El Concepto de Representación. Madrid: CEPC, 1985.

PUTNAM, R. Making Democracy Work USA: Princeton University Press, 1994.

RICH, R.; HAMBLY, L; MORGAN, M. G. (coord.), Political Parties in the Pacific Islands. Australia: Anu e Press, 2008.

RIDOLA, P. Partiti Politici. In: AA.VV. Enciclopedia del Diritto. vol. XXXII, Milano: Giuffrè, p. 66-127, 1982. Le regole Costituzionali del Pluralismo Politico e le Prospettive del Diritto dei Partiti. Giurisprudenza Costituzionale. no 3. anno XXXVIII, mag/giu, p. 2959-2969, 1993.

ROSANVALLON, P. La contrademocracia. La política en la era de la desconfianza. Buenos Aires: Manantial, 2007.

ROUSSEAU, J-J. O Contrato Social. Sâo Paulo: Formar, 1980.

RYDEN, D. K. Representation in crisis - the Constitution, interest groups, and Political Parties. New York: University of NY Press, 1996.

SARTORI, G. Teoria Democrática. [s.l]: Fundo de Cultura Brasil/Portugal, 1962.

Parties and Party Politics: A Framework for Analysis. New York: Cambridge University Press, 1976. 

494, 1997 .

Pluralismo, Multiculturalismo e Estranei. Rivista Italiana di Scienza Politica, a. XXVII, no 3, dic, p. 477-

Elementos de teoría política. Madrid: Alianza, 2005.

SANTANO, A. C. O financiamento da política. Teoria geral e experiências no Direito Comparado. Curitiba: Íthala, 2014.

SCARROW, S. E. The nineteenth-century origins of modern political parties: The unwanted emergence of partybased politics. In: AA.VV. Handbook of party politics. Great Britain: Sage, p. 16-24, 2006.

SCHUMPETER, J. A. Capitalismo, Socialismo y Democracia. Barcelona: Folio, 1984.

SOSPEDRA, M. M. Introducción a los Partidos Políticos. Barcelona: Ariel, 1996.

STOKES, S. C. Are Parties what's wrong with democracy in Latin America?. Guadalajara, 1997. Disponível em: <http://lasa.international.pitt.edu/LASA97/stokes.pdf> Acesso em 12 abr.2013.

TORCAL, M.; MONTERO, J. R.; GUNTHER, R. Los Sentimientos Antipartidistas en el Sur de Europa. In: AA.VV., Partidos Políticos: viejos conceptos y nuevos retos. Madrid, Trotta, p. 245-276, 2007.

VALVERDE, R. Del Boletín Electoral Latinoamericano XVII (1997) al Cuaderno de Capel 53 (2008): Una lectura actualizada sobre la observación nacional electoral 10 años después. In: AA.VV. Lecciones aprendidas en materia de observación electoral en América Latina. Cuadernos CAPEL 53. San José de Costa Rica: IIDH/CAPEL, 2008. p. 103.1267.

VILLASANTE, T. R. Las Democracias Participativas: De la participación ciudadana a las alternativas de la sociedad. Madrid: HOAC, 1995.

VILLORIA MENDIETA, M. La Corrupción Política. Madrid: Sintesis, 2006.

VIRNO, P. A grammar of the multitude. For an analysis of contemporary forms of life. Los Ángeles: Semiotext(e), 2004. Disponível em: < http://ccs.ukzn.ac.za/files/GrammarOfTheMultitude.pdf> Acesso em 08 jan.2015.

WARE, A. Political Parties and Party Systems. Great Britain: Oxford University Press, 1996.

Conclusions. In: BURNELL, P.; WARE, A. (eds.). Funding Democratization. UK, Manchester University Press, 1998.p. 232-251.

WENMAN, M. William E. Connolly: Pluralism without Transcendence. The British Journal of Politics \& International Relations, v. 10, p. 156-170, 2008.

WRIGHT, G. C. Charles Adrian and the study of non partisan elections. Political Research Quarterly. v. $61, \mathrm{n}^{\circ}$, p. 13-16, march, 2008.

WHITE, J. K. What is a political party?. In: AA.VV., Handbook of party politics. Great Britain: Sage, p. 5-15, 2006.

YANAI, N. Why do Political Parties Survive? An Analytical Discussion. Party Politics, v. 5, no 1, p. 5-17, 1999.

Trabalho enviado em 21 de julho de 2015.

Aceito em 11 de agosto de 2016. 